\title{
A PSICANÁLISE E O DESAMPARO FRENTE À CRISE DE VALORES E IDEAIS NA ATUALIDADE
}

\section{Érico Bruno Viana Campos}

Universidade Estadual Paulista "Júlio de Mesquita Filho" Lucianne Sant Anna de Menezes

Universidade Federal de Uberlândia

Josiane Cristina Bocchi

Universidade Estadual Paulista "Júlio de Mesquita Filho"
Recebido em: 30/07/2020

$1^{\text {a }}$ revisão em: 28/09/2020

Aceito em: 08/11/2020

\section{RESUMO}

A psicanálise tem privilegiado o conceito de desamparo para tecer considerações ontológicas e éticas fundamentais sobre ser humano, constituindo um operador importante para refletir sobre as condições subjetivas da sociabilidade contemporânea, marcada por uma transição nos valores e ideais normativos sustentados pelas instituições modernas. O objetivo deste artigo é trazer uma reflexão baseada em três eixos complementares para a consideração do sofrimento a partir desse operador essencial: (1) a concepção de sublimação como um destino pulsional; (2) a concepção de trabalho como condição de elaboração psíquica e criação do laço social; (3) os limites e condições da razão diagnóstica na consideração do sofrimento psíquico. Conclui-se que o aprofundamento da compreensão do trabalho sublimatório sobre as pulsões, abordando seus efeitos simultaneamente nas dimensões individual e coletiva, seja um encaminhamento possível para contribuir no sentido de constituição de vínculos sociais integrativos e propositivos de novos ideais para a cultura da atualidade.

Palavras-chave: psicanálise; desamparo; sublimação; trabalho; saúde mental. 


\title{
PSYCHOANALYSIS AND HELPLESSNESS TOWARDS TODAY'S VALUES AND IDEALS CRISIS
}

\begin{abstract}
Psychoanalysis has privileged the concept of helplessness to weave fundamental ontological and ethical considerations about human beings, constituting an important operator to reflect on subjective conditions of contemporary sociability, marked by a transition in normative values and ideals supported by modern institutions. This article aims to bring a reflection on this essential operator based on three complementary axes for the consideration of suffering: (1) the concept of sublimation as a drive destination; (2) the conception of work as a condition of psychic elaboration and creation of the social bond; (3) the limits and conditions of the diagnostic reason when considering psychological suffering. It is concluded that the deepening of the understanding of the sublimatory work on the drives, addressing their effects simultaneously in the individual and collective dimensions, is a possible way to contribute towards the constitution of integrative social bonds and propositions of new ideals for today's culture.
\end{abstract}

Keywords: psychoanalysis; helplessness; sublimation; labour; mental health. 


\section{EL PSICOANÁLISIS Y DESAMPARO FRENTE A LA CRISIS DE VALORES E IDEALES DE LA ACTUALIDAD}

\section{RESUMEN}

El psicoanálisis ha privilegiado el concepto de desamparo para elaborar consideraciones ontológicas y éticas fundamentales sobre ser humano, constituyéndose como un operador importante para reflexionar sobre las condiciones subjetivas de la sociabilidad contemporánea, marcada por una transición en los valores e ideales normativos sustentados por las instituciones modernas. Este artículo objetiva una reflexión basada en tres ejes complementarios para la consideración del sufrimiento: (1) la sublimación como un destino pulsional; (2) el trabajo como condición de elaboración psíquica y creación del lazo social; (3) los límites y condiciones de la razón diagnóstica en la consideración del sufrimiento psíquico. Se concluye que la profundización de la comprensión del trabajo sublimatorio sobre las pulsiones, abordando sus efectos simultáneamente en las dimensiones individual y colectiva, sea un encaminamiento posible para contribuir en el sentido de constitución de vínculos sociales integradores y propositivos de nuevos ideales para la cultura de la actualidad.

Palabras clave: psicoanálisis; desamparo; sublimación; trabajo; salud mental. 


\section{INTRODUÇÃO}

Este ensaio teórico tem como objetivo apresentar reflexões derivadas de linhas de pesquisas psicanalíticas convergentes sobre o desamparo na constituição da subjetividade na atualidade, a partir de perspectivas complementares que tomam o sofrimento psíquico, o trabalho e a sublimação como eixos prioritários de investigação.

Temos trabalhado com a definição de que o desamparo seja uma condição geral no funcionamento psíquico de qualquer pessoa e se refere ao caráter da "ausência de ajuda" como possibilidade efetiva da vida psíquica, sendo que esta condição de desamparo pode se concretizar numa situação traumática, relativa ao excesso pulsional que não pôde ser simbolizado. Nesse sentido, o desamparo pode ser caracterizado pelos sentimentos de perda, profundo desalento e impotência, aliados a ameaça à integridade psíquica do eu e à perda do senso norteador das ações e dos juízos de valor, além da crença ou percepção de que a transposição de tal estado é impossível ou depende exclusivamente do auxílio externo.

$\mathrm{Na}$ teoria psicanalítica, a concepção de desamparo (Hilflosigkeit) expressa a dimensão fundamental e insuperável sobre a qual repousa a vida humana: a condição de existência do sujeito no mundo (ou seja, na cultura ou civilização) é apoiada em uma condição de desamparo do psiquismo. Tendo em vista que o sujeito é obrigado a uma renúncia pulsional como condição para viver em sociedade e, em consequência da satisfação pulsional frustrada, experimenta um desconforto que é sentido como um mal-estar (Unbehagen), ele estabelece uma relação de conflito interminável com a condição de desamparo. A mensagem freudiana é que, para viver, as pessoas criam possibilidades afetivas no enfrentamento desta condição fundamental, que diz respeito a uma dupla modalidade de destino frente ao desamparo: a aceitação (destinos criativos) e o evitamento (destinos funestos). Desse modo, uma terapêutica possível refere-se a uma espécie de gestão infindável do conflito: a 'gestão do desamparo' (Birman, 2006, Campos, 2013, Menezes, 2008, 2012). A problemática do desamparo tem dupla face: a face erótica e sexual, que diz respeito a um lugar infantil e à sexualidade traumática vinda da mãe - este é o desamparo original estruturante do psiquismo; e a face da falta de garantias do sujeito sobre o existir e sobre seu futuro, que é obrigado a uma renúncia pulsional como condição para viver em sociedade e em consequência da satisfação pulsional frustrada, o sujeito experimenta o mal-estar.

$\mathrm{Na}$ atualidade, a Psicanálise tem privilegiado o conceito de desamparo para tecer reflexões ontológicas e éticas fundamentais sobre o homem enquanto um ser cultural, de modo que o desamparo tem sido um operador importante para refletir sobre as condições subjetivas do laço social contemporâneo, que é caracterizado por uma transição no âmbito dos valores em que os ideais normativos coletivos que eram garantidos pelas instituições modernas agora encontram-se em crise. 
Essa crise da subjetividade moderna apresenta-se de diversas maneiras, com destaque para seus efeitos disruptivos no tecido social e as expressões afetivas derivadas que temos caracterizado como desintegração e desilusão, no âmbito da representatividade simbólico-institucional e nos processos de subjetivação contemporâneos.

A desintegração diz respeito à dissolução na consistência e na permanência das marcas identitárias individuais e coletivas que sustentam as subjetividades. Tratase sobretudo de um efeito sobre o eu, que passa a ser marcado pela condição de difusão e fluxo identitário, tomado por uma demanda de reinvenção e readaptação constantes em um cenário de progressiva escassez de garantias de suporte emocional, simbólico e material. Já a desilusão diz respeito a essa falha na sustentação subjetiva e ontológica, que se efetiva por meio do enfraquecimento e perda dos referenciais identificatórios que se colocam como parâmetros idealizados para o pensamento e a ação. A perda dos ideais ético-normativos coloca uma situação não apenas de ausência de integridade e continuidade identitária, mas sobretudo de perda da referência na filiação à tradição cultural e de horizontes espaço-temporais em direção ao passado e ao futuro. Os processos ligados ao que descrevemos como desintegração e ilusão têm efeitos ontológicos, pois interferem na percepção subjetiva e nas condições materiais que sustentam formas de reconhecimento e de existência concreta e política de indivíduos e de certos grupos. Isso resulta em uma fratura na ilusão de que o mundo está lá, tolerando e permitindo ser recriado e transformado para viabilizar a satisfação e a pertença.

Do ponto de vista psicanalítico, essa condição tem sido descrita e definida a partir de uma teoria da constituição do ego e das suas instâncias ideais a partir do complexo de Édipo como condição estruturante subjetividade, tanto no âmbito pessoal, individual e personalístico, quanto no âmbito grupal, coletivo e social. A chave de interpretação e leitura é a de uma revolução nos próprios princípios reguladores da ordem social. Por um lado, a diretriz fundamental da renúncia da satisfação pessoal em prol da segurança social e do bem comum é posta em questão e aparentemente invertida, fomentando-se o prazer no risco, no desafio e na transgressão como um novo imperativo categórico. Por outro, a crise nos valores modernos e referenciais morais é concebida como um declínio da função paterna e dos ideais imaginários que a sustentam e das instituições que os encarnam e realizam. Discute-se então a quebra do paradigma edípico e neurótico de regulação das subjetividades e se avança no espectro amplo, difuso e multifacetado do narcisismo em suas dimensões teórica, clínica e cultural. É nesse sentido que os aportes filosóficos e sociológicos sobre a crise da modernidade (a sociedade do espetáculo, a cultura do narcisismo, a sociedade de controle, a era do vazio e tantos outros) vieram renovar e ampliar a reflexão psicanalítica sobre e a cultura e a sociedade. O essencial é a afirmação de que na contemporaneidade emerge uma cultura narcísica e performática, marcada pelo imperativo do risco e da satisfação irrestrita e imediata, com esvaziamento da dimensão alteritária e solidária dos laços sociais. 
No individualismo exacerbado e autocentrado de uma cultura de valores efêmeros e voláteis, configuram-se novas formas de sofrimento, em que a dimensão histórica e a narrativa intrapsíquica se esvaziam em direção ao registro imediato e visível do corpo e da ação. Isso é particularmente evidente nas chamadas psicopatologias contemporâneas, em que os sintomas clássicos da psicopatologia neurótica marcados pela riqueza do conflito psíquico entre representações mentais e censuras morais - se esvaem desse circuito reflexivo-introspectivo e se espraiam em sintomas da ordem da afetividade desvinculada ou inibida. Trata-se de um movimento duplo de esvaziamento na compreensão do sofrimento, tanto de sua dimensão psíquica (reflexiva, singular e pessoal) quanto de sua dimensão social (histórica, cultural e política), com um recrudescimento de sua dimensão corporal, mas um corpo que é entendido estritamente a partir de uma perspectiva orgânica e funcional. Movimento este cujo corolário é a codificação dos sintomas a partir de uma psicopatologia estritamente descritiva, sindrômica e atomista, onde o que conta é a relação de alguns sinais e sintomas específicos.

É nesse contexto que a problemática do desamparo ganha relevo como expressão paradigmática do mal-estar contemporâneo. Diante da perda de referências simbólicas consistentes e persistentes; diante das mudanças na forma de estabelecer vínculos e de inserção das pessoas no trabalho; emerge o vazio, a falta de sentido e de esperança; em suma, o desamparo. Nossa proposta é trazer reflexões em alguns níveis desse complexo campo de problematização. Em primeiro lugar, abordando a dimensão da implicação subjetiva do corpo e de suas formas de sofrimento, como se verifica no aumento dos quadros clínicos de somatização e dor crônica. As lesões auto infligidas e os distúrbios da imagem corporal representam formas contemporâneas de subjetividade em que a relação entre corpo e sofrimento humano são levadas ao limite da tensão vital. Nessas formas de sofrimento, o corpo desponta como um último lugar para produzir visibilidade para condições que não puderam circular de outros modos, no campo das trocas simbólicas ou através da fala. Em segundo lugar, a partir de sua relação com o trabalho que nas condições atuais do mal-estar tende a ser amorfo, sem contorno e definição claros, promove a informalização e a vivência de precarização, quadro que pode ser compreendido como um dos efeitos do neoliberalismo na saúde dos trabalhadores e trabalhadoras, como o desgaste mental e a corrosão da subjetividade. Um dos efeitos disso é o complexo fenômeno social global do processo da precarização do trabalho, que sob o ponto de vista da psicanálise, pode ser compreendido como um dos efeitos do mal-estar atual no campo do trabalho. Por fim, apontamos o resgate da concepção psicanalítica de sublimação, enquanto um articulador entre a demanda pulsional corporal e os destinos sociais. Nesse sentido, enfatizaremos a pertinência de tomar a sublimação como mecanismo de erogeneização e de ligação da dimensão traumática da pulsão de morte por meio do vínculo com os objetos, como forma de pensar uma via de construção de vínculos intersubjetivos e de lidar com o desamparo estrutural no laço social. 


\section{CORPO, TEMPO E SOFRIMENTO}

Nossa investigação teórica e clínica sobre as formas contemporâneas de sofrimento psíquico tem colocado em evidência o registro imediato e visível do corpo e da ação, na forma do adoecimento físico, da dor crônica e de sofrimentos de caráter hipocondríaco. Vamos sistematizar alguns apontamentos para refletir sobre a produção de um sujeito que sofre através de seu corpo, bem como para discutir a relação entre tal economia psíquica e a produção de uma normatividade social que leva a formas individualizantes de subjetividade nas quais o sofrimento é levado ao limite da tensão corporal e psíquica.

A experiência de sofrimento tem sinalizado que a capacidade de simbolização e de formação de narrativas subjetivas encontra-se em crise e sendo substituída pelos registros do corpo, do somático e da ação. A sintomatologia ligada a esses registros não é exatamente nova. Ela traduz-se por sintomas clínicos, tais como as automutilações, a ideação de morte, os relatos de vazio ou inadequação subjetiva, perturbações no sentimento de identidade e no adoecer físico. No entanto, a experiência subjetiva relacionada a estas manifestações clínicas destoa dos sintomas histéricos e obsessivos clássicos, que envolviam um conflito com o desejo ou com a lei, mas sempre em uma referência à relação com o outro. Em síntese, as formas depressivas, compulsivas e somatizantes - tão prevalentes em nossa época - revelam que o sofrimento contemporâneo apresenta um traço notadamente individualizante e solitário.

Mas qual relação se pode estabelecer entre sofrimento e individualismo no âmbito do discurso social vigente? Domingos Infante descreve a "produção de um discurso enaltecendo um individualismo que nada tem do individualismo do cultivo da interioridade, do individualismo até aqui conhecido" (Infante, 2011, p. 67). O autor refere-se a uma forma de individualidade narcísica e performativa, em que todos se sentem no direito de reivindicar sua imagem e forma corporal. Também é possível identificar uma dimensão sociopolítica no sofrimento humano, a qual parece estar imanente a certos processos emergentes de subjetivação, caracterizados por relações sociais instáveis e posições binárias: o ganhador e o perdedor (a figura do loser), o produtivo e o improdutivo, acrescentando-se ainda a esfera do dominado e dominante, por referência às relações de sujeição e de controle. Contudo, essas posições não são excludentes, pois o discurso contemporâneo favorece uma flexibilização extrema do campo identificatório.

A esse respeito, é possível se identificar com padrões antagônicos, concomitante ou alternadamente. O importante é o valor de impregnação da identificação - seu valor de marca que se volta sobre a imagem corporal. Vladimir Safatle (2016), ao discutir a flexibilização de padrões de identificação, relata que nos anos 1990, as campanhas de grandes marcas publicitárias (como Benetton, Versace e Calvin Klein) veicularam representações de beleza que se tornaram hegemônicas, através de representações sociais do corpo desvitalizado, tecnoplástico e ambíguo, ao mesmo tempo em que investiam em valores contrários: a imagem da família, do 
contato com a natureza, da busca de equilíbrio. A ideia era justamente "permitir ao consumidor identificar-se com a marca sem, necessariamente, identificar-se com um de seus polos" (Safatle, 2016, p. 155). Segundo o autor, o posicionamento desse tipo de campanha não era incidir em valores exclusivos, mas bipolares, "porque os sujeitos estão presos a uma lógica de aceitação simultânea da norma e do desejo de sua transgressão. A publicidade compreendeu isso" (Safatle, 2016, p. 156).

Aquela publicidade parece ter entendido que mais importante do que vincular marca ao produto era ofertar um campo de identificações e, assim, ensejar uma abertura ao horizonte de experimentação e de indução à busca de novas imagens de si e de possíveis performances sociais. Dessa forma, uma outra representação latente no campo identificatório da contemporaneidade é justamente a ideia não se fixar, de não parar. Desempenho é a palavra e, nesse contexto, chegamos a uma das principais características do pensamento neoliberal presente no discurso social contemporâneo, qual seja, o não repouso. Dardot e Laval (2016) apontam que uma das características da forma neoliberal é o empreendedorismo e a administração social, tendo a concorrência interiorizada como norma universal das condutas.

Por esta via, os princípios aplicados à lógica da economia seriam transportados para o campo da subjetividade e nisso chegamos às máximas sobre os relacionamentos: o encontro com o outro tem que acrescentar, somar: "Tal pessoa não agregou valor a minha vida" ou "Perdi tempo nesse relacionamento". Desse modo, os princípios éticos que norteiam a concepção de intimidade estariam, de certa forma, impregnados pelos imperativos da autonomia, da competitividade $e$ da auto eficácia. Destarte, a promessa de autorrealização e a crença no ganho irrestrito, em detrimento das experiências de troca e empatia, venham a compensar o ônus gerado para o sujeito e seu corpo. Para Ehrenberg (2004/2009), a explosão da demanda por saúde mental e melhora do si é uma responsabilidade que pesa sobre cada um.

Safatle (2016), Dardot e Laval (2016) assinalam que o pensamento neoliberal não se restringe a um regime de regulação de trocas no campo da economia, mas estende-se para a cultura e para setores da vida social (como o lazer, trabalho, relações interpessoais, a área da saúde), espaços nos quais o sistema econômico opera como uma forma de vida (Dunker, 2015, Safatle, 2016). Nesse sentido, parece existir uma política para o sofrimento, como na gestão de afetos como o desamparo, a culpa, a vergonha e as inibições. A esse respeito, a intensificação do discurso da autonomia individual apresenta-se como um dos fundamentos de uma matriz produtora de sofrimento:

Cabe apenas ao indivíduo a responsabilidade pelo fracasso da sua tentativa de autoafirmação no mundo do trabalho, na família e na vida social. O discurso social é constituído a partir da incitação à auto-expressão e ao empreendedorismo de si. Se a afirmação não se realiza, foi por culpa do indivíduo (Safatle, 2016, p. 190). 
Se o sucesso só depende do si mesmo, o sujeito passa a ser culpado não mais pela realização dos seus desejos, mas por ele não os ter realizado. A norma social reguladora do desejo não é mais a contenção, mas a extração de um plus ultra de si mesmo. Temos um modo de organização social que altera a produção do sofrimento psíquico, e este se desloca da matriz repressiva (proibido versus permitido), característica do modelo freudiano das neuroses da interdição do desejo - para uma nova matriz de polarização, em que o conflito será possível/impossível (Safatle, 2016). Possivelmente, trata-se de uma nova matriz superegóica que não está ligada à capacidade de autocontrole dos impulsos, mas sim à obrigação de fazer e de sustentar uma imagem ideal de si. Por um lado, como efeitos dessa norma social na economia psíquica, tem-se uma implosão psíquica pela via do predomínio de formas paralisantes de sofrimento, como nas fobias, depressões e cortes na superfície corporal. Por outro lado, produz-se montagens mais excitadas e desorganizadas, como nas categorias clínicas descritas no sofrimento do borderline, nas compulsões e na bipolaridade. Em termos dos efeitos dessa nova matriz social do desejo para a percepção subjetiva e para os processos de constituição psíquica do eu, trata-se de estar ora vazio, ora saturado. Mas o cheio demais também é uma forma de esvaziamento subjetivo. Nesse sentido, nos parece que os estados de esvaziamento e de excesso caracterizam ou definem uma categoria central de sofrimento na atualidade.

O deslocamento do eixo conflitual da matriz do superego - da contenção para a injunção, como anteriormente descrito - coloca em evidência a vergonha, o sentimento de impotência e as sensações de inadequação. Ele ainda incorre em modalidades distintas de culpa: uma ligada às contradições entre os ideais e o desejo e a outra "ligada ao usufruto dos objetos" (Infante, 2011, p. 69). Quando o sujeito acha que não está gozando tanto quanto poderia diante do que lhe é oferecido. E por esta via, o sujeito responde mais prontamente às exigências que se impõem do campo do trabalho e seus desafios e dos apelos ligados ao marketing e ao consumo. Ora, estaria descrita aqui uma situação paradigmática para pensar as relações entre economia libidinal e economia política? Vejamos.

A propósito, as transformações da figura de autoridade e o declínio dos ideais baseados na renúncia pulsional, libidinal e agressiva - em nome do bem comum cederam seu lugar para uma vertiginosa captura da pulsionalidade pela via do ideal de super dimensionar a experiência e a satisfação individual. Simplesmente, goze! Para ter clareza, é preciso retomar a concepção freudiana de pulsão, como em Os instintos e seus destinos (Freud, 1915/2010), para sublinhar as características originárias da pulsão: a fonte (de natureza corporal), o objeto (não previamente definido e variável), a força (pressão) e a meta (a satisfação). Sendo assim, a ordem pulsional se apresenta pelo registro da fragmentação, do polimorfismo e, devido à sua ligação com o corpo, a pulsão também está ligada a uma temporalidade infinita, ou ininterrupta: a pulsão refere uma tensão que não cessa, ela não tem início e nem fim propriamente. Um fenômeno similar encontramos na angústia que perdura na experiência dolorosa e no sofrimento psíquico decorrente da relação com o trabalho e sua confusão de limites entre descanso e atividades laborais. 
As características da ordem pulsional, então, quando cooptadas pelo discurso social do empreendedorismo e da gestão de si, têm consequências diretas para a produção de um sujeito e constituem-se como fator explicativo decisivo para a leitura do sofrimento psíquico à luz da cultura contemporânea. Em termos da articulação entre estruturas psíquicas e o campo social, encontramos na clínica e na experiência social, a incidência de sintomas de ruptura com a estrutura alteritária e a produção de uma retração narcísica. E como referido ao início desta seção, tal fenômeno está associado às formas individualizantes de sofrimento, tais como nas fobias sociais, nos estados depressivos ou irruptivamente ansiosos, nas formas autistas e nas escarificações corporais, para ficar nesses exemplos. Esta cultura atual, excessiva e indiferente, ao mesmo tempo está voltada para rituais de cuidados com a saúde e a boa forma corporal, aspecto este que não desenvolveremos no presente trabalho.

Este trabalho dirige a atenção para o aparecimento de formas de adoecimento e de sujeição, ligadas à extração do que há mais íntimo no humano - o corpo, o tempo e o sofrimento. O corpo parece estar submetido a uma modelagem que prescinde do desejo, regulado para a intensificação das formas exteriores, a beleza e a boa forma. Nota-se que tal incitação está acompanhada pela alta prevalência de distúrbios alimentares, a vigorexia, cirurgias estéticas e mesmo as estatísticas de cirurgia bariátrica, muito elevadas no Brasil. Se não existe exercício de poder sem uma forma de montagem de corpos e de certos regimes de desejo, então: "Não há poder que não crie uma 'vida psíquica' através das marcas que deixa nos corpos" (Butler, 2017, p. 136).

O aumento da incidência de quadros psicossomáticos - como na dor crônica ou fibromialgia - reflete indicadores de como o corpo é invocado para produzir um traço de visibilidade para condições que não puderam obter outro modo de reconhecimento nos espaços de circulação social. É preciso lembrar do aspecto de experiência privada da dor, ela é o mais subjetivo dos sintomas (Barreto \& lannini, 2017). Nossa experiência mostra que os pacientes com dor têm um extenso histórico de serem avaliados por vários especialistas (medicações, psicoterapias) e manter-se com a sintomatologia. Não seria a queixa que aparece sob a forma de adoecimento somático - com perda na experiência narrativa - uma maneira de denunciar um obscurecimento do sujeito? O corpo que se faz evidência excessiva nos laudos médicos é seguido por um regime intermitente de reconhecimento do sofrimento, na medida em que a normatividade operante no regime do modelo biomédico é a que decide o que será tratado, o que recebe atenção (os sintomas, a doença) e o que será invisibilizado (o sujeito e a dor psíquica).

No que tange à extração do tempo, a aceleração dos processos no cotidiano e as exigências de uma nova administração social do tempo - as múltiplas tarefas imprimem uma efração na temporalidade psíquica, gerando desconexões e perdas na vivência da experiência temporal. Esse fenômeno está relacionado à emergência de estados depressivos, ansiosos e distúrbios da atenção. Os modelos diagnósticos oficiais - como o DSM e o CID, produzidos pela Associação Psiquiátrica Americana 
(APA) e pela Organização Mundial da Saúde (OMS), respectivamente, fundamentam-se numa concepção descritiva, pragmática e apressada da classificação dos transtornos. É o que se vê na manipulação do critério temporal como diretriz clínica para a identificação dos sintomas. Os períodos exigidos para a manifestação sintomática tornam-se cada vez mais breves. Para fechar o diagnóstico das depressões e da bipolaridade, o DSM exige o mínimo de duas semanas.

Vale ressaltar que a nossa época tende a transformar as experiências de sofrimento em insígnia de uma patologia a ser tratada e faz proliferar figuras diagnósticas que se dissolvem no encontro com a realidade (Bocchi, 2018). Há uma epidemia de transtornos, co-existindo em paralelo com crescimento do mercado dos fármacos e dos instrumentos diagnósticos que os identificam e classificam. Uma das modalidades predominantes de reconhecimento do sofrimento na atualidade diz respeito às transformações do sistema diagnóstico desde o final do século passado, com a mudança de paradigma trazida pelo DSM-III, e sua ruptura com a psicanálise. A multiplicação de novos transtornos responde a uma demanda social "não apenas medicamento e alívio, mas de sentido" (Russo \& Venâncio, 2006, p. 475).

A dimensão passional do sofrimento é capturada pelo fenômeno da medicalização. A significação ontológica e social latente das demandas do sofrimento passam a ser interpretadas apenas como disfunção (hormonal, neuroquímica, etc.). Mesmo a substituição do termo doença mental (mental disease), desde o DSM-III, por transtorno (mental disorders) não trouxe o afastamento do estigma da doença mental. Pelo contrário, houve uma multiplicação das entidades clínicas e uma repatologização: é mais aceitável receber o diagnóstico de um transtorno (ou mais de um) do que de uma doença mental. O próprio termo é elástico e encobre que se trata, afinal, de um pathos que continua como sinônimo de doença, mas "Um diagnóstico não nos informa tão somente sobre uma doença supostamente dada na natureza; ele a produz" (Infante, 2011, p. 63).

A nova diagnóstica recria pautas identitárias e novas atuações. De forma irônica, pode-se dizer que aparentemente elas incluem, e não mais excluem. Existe uma audiência cativa em relação às histórias pessoais de superação de uma depressão, do pânico; elas se tornam vias de auto expressão. Parece que o caminho adotado foi ocupar as categorias de sofrimento, individualizar sua gestão e tratamento, ao invés de reiterar as antigas estratégias de internamento e exclusão do convívio social, agora menos toleradas.

Assim, a experiência de sofrimento não está isenta à ótica neoliberal e à gestão sob a forma-mercadoria, pois o próprio sofrer tem sido usado como fator de produtividade, de reinserções e valoração social. Haveria também uma globalização das formas de sofrimento "cada vez mais, cada um reconhece-se em conjunto de signos clínicos dotados de valor diagnóstico" (Dunker, 2015, p. 23). A vida contemporânea, em sua versão neoliberal, determina um sistema de regras de 
reconhecimento/não reconhecimento, assim como uma cultura em que se difunde formas de individualização e estruturas normativas, através da produção crescente de novas categorias diagnósticas e de re-designações para o mental. Trata-se de uma razão diagnóstica que não esconde pretensões corretivo-classificatórias através da promoção de novos conceitos de saúde, comportamento e o ideário de bem-estar. Tal fenômeno parece responder a uma neopolítica para o sofrimento e o corpo no âmbito social.

A lógica diagnóstica formal descritiva dos manuais de classificação dos transtornos mentais, bem como os pressupostos quantitativos e pragmáticos que os sustentam, retiram do sofrimento seu caráter afetivo-passional, apagando as marcas de desamparo. Com isso, des-subjetiva aquele que sofre, conformado a um núcleo reduzido de sintomas e outras inabilidades funcionais e sociais. Trata-se o sofrimento humano como se não fosse tal, como se ele não fosse sofrimento, portanto desumaniza-se o sofrimento.

Isso nos coloca diante de posições ético-políticas necessárias para a compreensão do desamparo no momento atual, frente à crise e dissolução do eu e de ideais da cultura contemporânea de massa. Uma realidade que também incide nas relações entre sofrimento e o universo do trabalho e das possibilidades de elaboração de novos destinos sublimatórios, como demostraremos a seguir.

\section{PRECARIZAÇÃo DO TRABALHO, DESAMPARO E MONTAGEM PERVERSA}

Do ponto de vista freudiano, o trabalho é um elemento essencial da vida humana, tendo em vista sua função estruturante, seja ao possibilitar destinos para as pulsões, seja ao assegurar ao sujeito um lugar no circuito social. É, portanto, uma das peças fundamentais na problemática da identidade e na manutenção da civilização.

A essência da noção freudiana de 'trabalho' (Arbeit) reside nas operações e processos relativos ao psiquismo, diz respeito portanto, ao funcionamento psíquico, a todo tipo de trabalho psíquico (psychischer Arbeit): trabalho do sonho (Traumarbeit), trabalho do luto (Trauerarbeit), elaboração psíquica (Bearbeitung/ Ausarbeitung/Aufarbeitung/psychishe Verarbeitung), perlaboração (Ducharbeiten), trabalho intelectual (intellektueller Arbeit) e trabalho profissional, ofício ou trabalho vocacional (Berufsarbeit), dentre outros (Menezes, 2008).

O trabalho como ofício (Berufsarbeit) é uma ocasião para elaboração psíquica; constitui-se em um dos meios de expressão do sujeito. Freud marca que o trabalho pode ser um meio de sublimação se o sujeito estiver afetivamente ligado a ele, portanto, é necessário que haja erotismo na relação com o trabalho: "A atividade profissional traz particular satisfação quando é escolhida livremente, isto é, quando permite tornar úteis, através da sublimação, pendores existentes, impulsos instintuais subsistentes ou constitucionalmente reforçados" (1930/2010, p. 81). 
Em carta para Pfister (6/5/1910), Freud dá mostras de que seja qual for o trabalho, para ele, constitui-se no alimento de todos os dias, em um instrumento para a conduta da vida, para lidar com as pulsões:

Não posso conceber qualquer espécie de satisfação em uma vida sem trabalho. No meu caso andam juntos imaginação criativa e trabalho; não tenho prazer em nada mais. Isso seria uma prescrição para felicidade, não fosse o terrível pensamento de que a produtividade de uma pessoa depende inteiramente dos estados sensíveis (Freud citado por Jones, 1953/1989, p. 392, grifos nossos).

Note que Freud considera o trabalho como fonte de satisfação pulsional, privilegiando sua satisfação pessoal, a obtenção de prazer. O que o autor sublinha é a importância do trabalho para a economia da libido, aspecto que ele teoriza em O mal-estar na civilização:

Não havendo uma disposição especial que prescreva imperiosamente a direção dos interesses vitais de alguém, o trabalho acessível a todos pode ocupar o lugar que the é proposto pelo sábio conselho de Voltaire. Não é possível, nos limites de um panorama sucinto, examinar satisfatoriamente a importância do trabalho para a economia libidinal (Freud, 1930/2010, p. 81, grifos nossos).

Ele alude ao conselho de Voltaire, no contexto de suas reflexões a respeito do sofrimento humano. Tendo em vista que, em vários momentos, a vida se torna árdua e difícil, o pai da Psicanálise nos aconselha a não dispensar medidas paliativas que nos ajudem a suportá-la, como: "poderosas diversões, que nos permitem fazer pouco de nossa miséria, gratificações substitutivas, que a diminuem, e substâncias inebriantes, que nos tornam insensíveis a ela." (Freud, 1930/2010, p. 20). Segundo o autor, Voltaire tinha tais derivativos em mente quando, ao terminar seu Candido, deixou o conselho para cultivarmos nosso próprio jardim. E acrescenta que a atividade científica também é um derivativo desta espécie. O trabalho, portanto, é um derivativo poderoso para lidar com a vida. Viver requer trabalho (Arbeit).

A "ênfase no trabalho" constitui-se em uma técnica na arte de viver, uma técnica para afastar o sofrimento, agindo nos impulsos por meio dos deslocamentos "para o trabalho e os relacionamentos humanos a ele ligados [de] uma forte medida de componentes libidinais - narcísicos, agressivos e mesmo eróticos." (Freud, 1930/2010, p. 81). O trabalho, portanto, é tão importante para a economia pulsional quanto é para a preservação e justificativa da vida em sociedade.

Pelo exposto, o trabalho pode ser compreendido, como uma resposta sublimatória ao desamparo (Hilflosigkeit). Para Freud (1930/2010) o trabalho é um instrumento 
que o homem criou para lidar com seu desamparo (Hilflosigkeit) e viver em sociedade. Dessa maneira, o trabalho, pode ser fonte de saúde para o sujeito ao dar destinos criativos para o desamparo. Entretanto, nas condições atuais do malestar caracterizado pelo excesso pulsional e pela fragilidade de simbolização, o trabalho tende a ser amorfo, liquefeito, sem contorno e definição claros que, sustentado na flexibilidade e desregulamentação, promove destinos funestos para o desamparo, como a informalização e a vivência de precarização, um sofrimento de origem sócio-política, na linha de pensamento de Rosa (2016). Este quadro pode ser compreendido como um dos efeitos do neoliberalismo na saúde dos trabalhadores, como o desgaste mental e a corrosão da subjetividade, uma dimensão de perdas relativas ao mal-estar no campo do trabalho que assume uma direção marcadamente perversa (Menezes, 2012).

Como enfatizado, o neoliberalismo não se reduz a um sistema econômico, a práticas que definem o capitalismo contemporâneo na sua característica globalizada, mas o neoliberalismo é uma forma de vida que enquanto tal compreende uma gramática de reconhecimento e uma política para o sofrimento, de modo que se pode extrair mais produção e mais gozo do próprio sofrimento (Dardot \& Laval, 2016, Dunker, 2015, Safatle, 2016).

Tal aspecto torna-se visível nos resultados das pesquisas que temos orientado na interface da psicanálise com a saúde do trabalhador (campo multidisciplinar que tem como objeto de estudo o processo saúde-doença na sua relação com o trabalho), em específico, a partir das análises da disposição do processo de trabalho em diferentes categorias de trabalhadores, com destaque para o dimensionamento inadequado de pessoal, sempre insuficiente, que altera as jornadas de trabalho e intensifica os ritmos de trabalho, gerando sobrecarga e pressões que ao longo do tempo configuram o desgaste do trabalhador. Este tipo de organização do trabalho, fruto da reestruturação produtiva, configura um novo discurso de gestão nas palavras de Gaulejac "como ideologia que legitima uma abordagem instrumental, utilitarista e contábil das relações entre o homem e a sociedade" (2007, p. 27). Quer dizer, o gerenciamento como tecnologia do poder entre o capital e o trabalho, de modo que a finalidade é conseguir a adesão dos trabalhadores às exigências da empresa, como fica expresso na frase 'vestir a camisa da empresa'. Dessa forma, a gestão dá um sentido para a vida das pessoas. A economia política se torna uma economia gestacionária em que as condições contábeis e financeiras importam mais que as considerações humanas e sociais.

O poder e a ideologia gerencialista levam ao desgaste da subjetividade do trabalhador, como aponta Seligmann-Silva (2011) a partir do ponto de vista da saúde mental relacionada ao trabalho (SMRT) e que, sob um olhar da psicanálise, leva o sujeito-trabalhador ao abismo do desamparo, restando-lhe como proteção desta condição concretizada em uma situação traumática, a posição de servidão.

O que estrutura o projeto neoliberal são ideais e valores derivados dos princípios da concorrência e que, a partir de certos mecanismos, como, por exemplo, o 
mecanismo de dominação perversa, instalam-se nas relações sociais. Desse modo, a vida passa a ser uma relação que deve apresentar um balanço. Tudo é mercado. E a pessoa passa a ser o empreendedor de si mesmo. A cultura do narcisismo vai sendo substituída pela cultura da indiferença. Uma das implicações disso é o quadro tendencial global de precarização estrutural do trabalho (Antunes, 2018) que, sob o ponto de vista da psicanálise, pode ser compreendido como um dos efeitos do mal-estar atual no campo do trabalho (Menezes, 2008).

Queremos marcar as condições para a escuta analítica fora do setting habitual do tratamento, em que o psicanalista oferece sua escuta na pólis por meio de práticas psicanalíticas denominadas de 'clínico-políticas' que se dão nos limites do campo psicanalítico e convidam ao diálogo com outros campos, como é o caso da saúde do trabalhador, levando ao aprofundamento da teoria psicanalítica e suas extensões, procurando criar dispositivos clínicos para a escuta da dimensão sóciopolítica do sofrimento (Rosa, 2016).

Neste caso, trata-se da escuta do trabalhador, deste sujeito submetido, excluído do modelo neoliberal, dos efeitos do discurso social das relações de poder e governabilidade do trabalho sobre os trabalhadores e de como podemos fazer a clínica, na proposta de uma clínica psicanalítica implicada nas conexões com a sociedade e a política, de modo que a direção da escuta nestas circunstâncias será poder separar a alienação estrutural do sujeito, da alienação ao discurso social e ideológico gerencialista (Gaulejac, 2007, Rosa, 2016).

A precarização do trabalho é um complexo processo que articula os aspectos social, econômico e político da vida humana, afetando a vida no trabalho e fora dele. Diz respeito ao aumento e a intensificação da força de trabalho que se estrutura em bases cada vez mais desregulamentadas, em que existe um processo de perda de estabilidade e da exploração do trabalho, tornando as relações de trabalho indefinidas e caracterizadas por um vínculo instável, flexível e frágil, portanto, com perda de direitos, adoecimentos de toda ordem e enfraquecimento das organizações coletivas (Antunes, 2018).

A precarização do trabalho é compreendida como um efeito nefasto da reestruturação produtiva e da globalização dos mercados financeiros que, no contexto brasileiro, tem suas especificidades em relação a outros contextos como o europeu, principalmente, por conta do processo de conformação das políticas sociais e das instituições de bem-estar no Brasil. Soma-se a isso, a referência à escravidão na gênese da sociedade e do Estado brasileiros que, sob o ponto de vista psicanalítico, pode ser compreendida como uma marca traumática que produz efeitos nas subjetividades, a exemplo da produção de formas de subjetividade marcadas pela passividade, assim como a reatualização do mecanismo de dominação perversa (Menezes, 2012).

A precarização do trabalho é considerada a implicação mais importante da flexibilização, que aliada à desregulamentação sustenta uma condição de trabalho 
precarizada visível, principalmente, nas formas de subcontratação, terceirização e, atualmente, pelo trabalho intermitente (contrato zero hora) que aliado a prevalência do negociado sobre o legislado são os dois aspectos piores da reforma trabalhista aprovada pelo governo Temer, o PLC 38/2017, o que traz efeitos deletérios a saúde dos trabalhadores, em especial, no aspecto mental, como o desgaste e a corrosão da subjetividade.

Para Menezes (2012), a precarização do trabalho seria uma das expressões do malestar atual, que assume uma direção marcadamente perversa, podendo ser compreendida como um dos efeitos da pulsão de agressão voltada para fora, mais especificamente, como pulsão de domínio ou 'vontade de poder', uma forma de manifestação da perversão no espaço social. Com isso, a autora insere a cadeia produtiva nas discussões psicanalíticas a respeito das manifestações da perversão no campo social. Ela defende a hipótese de que, sob a lente psicanalítica, há uma montagem perversa subjacente as relações que se estabelecem em uma cadeia produtiva, mais especificamente, entre as grandes empresas com seus fornecedores, tendo em vista que tais relações desvelam modalidades de satisfação ávidas pelo domínio, com ânsia de um poder absoluto, caracterizadas pelo acúmulo, excesso e usufruto do outro (trabalhador); que visa, portanto, à coerção a negar a alteridade do outro (trabalhador) e o dever de instrumentalizálo. A recusa da castração está assim, implicada na recusa da diferença, na recusa do outro, na recusa da alteridade. É a lógica da gestão gerencialista, em que prevalecem a pressão pela redução de custos, as leis do 'mercado livre' dominado pelas empresas que detêm o capital.

Os modos de subjetivação emergentes criam condições de possibilidade para laços sociais com características perversas, numa montagem em que só há duas posições possíveis: a do dominador e a do dominado, restando ao trabalhador a posição de submissão, de servidão, na medida em que a montagem perversa se caracteriza como uma aliança que encontra eco contra o desamparo, em que o mecanismo de dominação perversa constitui-se em um modo de evitar o confronto com o desamparo. Por um lado, formas que supondo triunfar sobre a condição de desamparo alimentam-se do horror do outro, acreditando assim dominar tal condição; e por outro, formas de subjetivação que acreditando se proteger do horror do desamparo privilegiam experiências de assujeitamento ao outro (Birman, 2006). Nesse sentido, o processo de precarização do trabalho poderia ser compreendido como um dos destinos funestos para o desamparo, sendo esta uma possível articulação metapsicológica entre o desamparo (Hilflosigkeit) e a precarização do trabalho (Menezes, 2012).

A dominação perversa é um mecanismo de manipulação do poder que sustenta a montagem perversa, por meio de uma estratégia que procura desarticular as respostas do dominado para sua condição de submissão. No campo do social a dominação perversa articula a dominação política com a dominação do sujeito (Menezes, 2012). 
Trata-se de estratégias políticas de deposição do sujeito que, na perspectiva psicanalítica são laços que enredam o sujeito simultaneamente no jogo afetivo e libidinal e também no jogo político, criando um discurso que equipara o campo simbólico da cultura e da linguagem, causando um efeito alienante sustentado por um equívoco na relação social com o outro que evita dar visibilidade aos embates sociais e políticos presentes em sua base (Rosa, 2016).

Se sob o ponto de vista sócio-histórico, o processo da precarização do trabalho aumenta os riscos e agravos à saúde dos trabalhadores, sob o prisma psicanalítico, favorece, estimula e intensifica uma condição de submissão no trabalho e uma forma de dominação perversa.

O trabalho hoje tende a ser fortemente marcado como uma questão de sobrevivência, expressando uma sujeição à necessidade, em que o trabalhador vai perdendo a modalidade 'bios', ficando reduzido à modalidade 'zoé', ao labor, à pura vida biológica (Agambem, 2017). A questão essencial é: como a sociedade do nosso tempo trata o trabalho: é um valor? Ou um custo? Se for um custo ele pode ser cortado em períodos de crise; mas, como valor o trabalho deve ter sentido dentro dele. Porém, se o trabalho como está hoje, é intermitente, qual o sentido que ele trará para o sujeito?

\section{TRABALHO, SUBLIMAÇÃo E CRIAÇÃo DE VÍNCULO SOCIAL}

Como se pode observar no percurso acima, a desintegração e enfraquecimento dos parâmetros modernos de subjetivação, centrada em uma concepção de sujeito psicológico que se insere e é reconhecido no campo social pelo valor de seu trabalho, traz uma modificação bastante significativa na forma de configuração do sofrimento contemporâneo e de suas diagnósticas. Tomando como referência a diferenciação proposta por Dunker (2015) entre mal-estar, sofrimento e sintoma, podemos entender que os sintomas psicopatológicos e o sofrimento social expressam modos de codificação e significação enredados pelas instituições culturais e seus sistemas de simbolização, sustentados em ideais reguladores. A crise da razão diagnóstica e a crise nas leis trabalhistas são duas facetas de um mesmo processo de transição e modificação em ideais organizadores da subjetividade em seu plano coletivo e em seu plano individual.

Entendemos que a Psicanálise opera em uma posição de resistência justamente na medida em que se opõe à plena des-subjetivação desses processos na direção de uma razão quantificadora, a saber, uma patologia que se reduz à mera descrição de sintomas para prescrição da regulação orgânica e de um trabalho que se reduz à mera potencialização de ganhos e reduções de perdas para fins de manutenção do capital. Há um potencial conluio perverso na conjunção entre essas duas lógicas no liberalismo contemporâneo e, nesse sentido, as seminais indicações de uma cultura narcísica e de uma sociedade performática centrada na visibilidade do espetáculo e no imperativo do risco e do gozo pleno vêm se confirmando a passos 
largos. É essa crise transicional que gera efeitos de desilusão e desintegração que são a marca do desamparo contemporâneo e que vêm ganhando destaque nas discussões do campo da psicanálise dos fenômenos sociais e culturais, nas suas variadas vertentes (aplicação, implicação, ampliação, etc.).

O que gostaríamos de propor como contribuição ao debate é o resgate da noção psicanalítica de trabalho como operador conceitual e eixo transversal de articulação entre as diferentes instâncias amalgamadas na entidade monolítica de uma abordagem "bio-psico-social" sobre a subjetividade humana. Para tanto, precisaremos revisitar os fundamentos metapsicológicos dessa teoria, para resgatar a sua originalidade no próprio Freud. Como se sabe, do ponto de vista psicanalítico, existe um trabalho originário e incessante sobre o corpo e as pulsões, assim como existe trabalho constante de elaboração sobre as representações psíquicas e suas expressões no corpo, no próprio psiquismo e na ação sobre o mundo compartilhado. Essa é a noção clássica da pulsão e seus diferentes destinos (Freud, 1915/2010), em uma concepção de circuito pulsional que muitas vezes foi e é tomada apenas como um sistema corpo-mente, ou seja, a pulsão sendo o conceito limite entre o somático e o psíquico. Contudo, essa visão de cunho estritamente psicológico sobre o circuito pulsional e, portanto, sobre a própria subjetividade, é algo que vai ser paulatinamente desconstruído e ampliado no período de revisionismo da teoria freudiana, de forma tal que as pulsões de vida e de morte do último dualismo são sobretudo princípios de ligação e desligamento, operando nos diferentes registros da subjetividade humana, isto é, no corpo material, no aparelho psíquico e na estrutura social (Campos, 2014). Nessa perspectiva, toda cultura é fruto do trabalho sobre as pulsões, como a conhecida metáfora freudiana sobre a drenagem e canalização dos rios urbanos deixa bem explícito.

Assim sendo, trabalho, do ponto de vista psicanalítico é elaboração psíquica de impulsos que brotam do corpo e incidem da realidade no intuito de dar-lhes sentido e destinação revertendo sobre a realidade compartilhada. Nesse sentido, sempre se destacou o trabalho de elaboração do sintoma como processo intrínseco à cura, porém defendemos que sua dimensão sócio-política como uma saída legítima do mal-estar deva ser resgatada em uma ampliação da clínica psicanalítica.

Em seu clássico ensaio, Freud (1930/2010) enumera de forma bastante esquemática as formas de lidar com o mal-estar e a castração. É possível depreender que para além de saídas radicais como o isolamento social e a aniquilação das pulsões em sua origem ou das saídas fortuitas e singularizadas como o refúgio na vida de fantasia ou nos vínculos amorosos, haveria basicamente dois grandes grupos de saídas possíveis: a via psicopatológica (adoecer neuroticamente ou psicoticamente) e a via das realizações culturais (produzindo a partir das identificações aos ideais morais, estéticos ou epistemológicos). Essa categorização descritiva apenas repõe aquilo que muitas vezes foi afirmado por Freud sobre a cura e a saúde, a saber, a ideia de que para não adoecermos 
precisamos amar e trabalhar. Com isso entendemos que há um distanciamento do parâmetro médico-psiquiátrico e a afirmação não só de uma perspectiva própria do senso comum moderno, mas também o que entendemos refletir uma inserção e reconhecimento social que vai além da mera adaptação à sociedade e no sentido de uma certa autonomia na gestão do desejo.

Curiosamente, no ensaio em questão, as realizações de trabalho e de sublimação não estão explicitamente elencadas. Em nossa interpretação isso se dá porque esses conceitos referem-se aos processos subjacentes a essas expressões e destinações pulsionais. É preciso trabalho elaborativo sobre as pulsões para produzir formas de sofrer (sintomas), amar ou de realizar. Neste último, Freud endossa as realizações artístico- culturais e científicas, contudo podemos entender que qualquer tipo de trabalho sobre a realidade material e social é uma expressão de elaboração pulsional. Mas o que importa é que essa última saída implica uma passagem do registro estrito do amor e da sexualidade e, portanto, depende de uma operação de sublimação.

Sublimação, em sua definição mais básica e conhecida, seria o destino da pulsão que resulta de uma transformação da meta de satisfação sexual e do objeto por um valorizado e reconhecido socialmente. Decorre dessa primeira acepção a ideia de dessexualização da libido como aspecto central nesse processo e a sua tomada em uma dimensão meramente descritiva e valorativa, que gerou uma dicotomia: ou bem a pessoa sublima ou por mal ela produzira sintoma. A questão é que a "capacidade" de sublimação, enquanto um processo metapsicológico e psicodinâmico, recebeu pouca atenção por parte da psicanálise, relegado a um atestado - algo como "aqui reconhece-se que a pessoa sublimou".

Retornando à origem freudiana, Loffredo (2014) mostra a pluralidade de figurações da noção de sublimação, indicando a configuração de pelo menos dois momentos nesse processo. O primeiro momento seria este que estamos descrevendo como o mais tradicional e que ficou para a história da psicanálise: a sublimação como um destino que é praticamente o mecanismo de defesa mais bem adaptado. Do ponto de vista do processo, trata-se de uma sublimação que acontece a partir da identificação com os ideais componentes do superego e, por isso, no registro edípico (Campos \& Loffredo, 2019). Isso quer dizer que é um processo de destinação da pulsão que ocorre baseado em um aparelho psíquico instaurado a partir da lógica do recalque e do retorno do recalcado, onde nesse retorno se efetiva uma transposição do registro da satisfação sexual de caráter fálico-genital para um objeto não humano ou atividade. A vinculação à realização da atividade e se produto se dá mediada pelos ideais morais, estéticos e de conhecimento ao qual a pessoa está identificada. O que interessa destacar para nossa presente discussão é que são processos sublimatórios bem assentados em um registro de simbolização propriamente dita, em que há substituições e transformações que operam prioritariamente sobre a libido investida em representações psíquicas, mediadas por ideais reguladores consistentemente introjetados, de forma a estabelecer um circuito mais ou menos estável de regulação do conflito. 
Já o segundo momento se delineia no período de revisionismo da obra freudiana a partir da consideração da constituição do ego e da ligação da pulsão de morte em libido. A sublimação passa a ser também um processo de erogeneização, de captura da pulsão de morte e sua transformação em libido narcísica por meio de processos de identificação. Trata-se então de uma identificação no nível da constituição do ego e sua relação com o ideal do ego em um nível narcísico de relação de objeto e de simbolização (Campos \& Loffredo, 2019). Nesse nível, não há ainda o suporte simbólico consistente viabilizado pelo par recalque-superego, estando, portanto, no âmbito do traumatismo, das angústias automáticas, da compulsão à repetição; em suma, do desamparo em sua dimensão mais originária. Contudo esse nível primário de sublimação é também vital para a instauração dos ideais egóicos e o vínculo com a realidade compartilhada. Evidentemente esse vínculo com a realidade compartilhada posteriormente será ressignificado e reposicionado a partir das regulações edípicas, mas o fato é que esses dois níveis de relação com a realidade - narcísica ou propriamente objetal - sempre estão presentes de forma complementar e em diferentes distribuições nos modos e momentos de subjetivação operantes nas pessoas. O que interessa destacar é que a crise nos ideais sócio-culturais da contemporaneidade, justamente por fomentar modos de relação narcísica e perversa com o corpo, o desejo e o trabalho, acaba produzindo formas de sofrimento onde a regulação do sistema ego e ideal do ego está em questão, em suas formas melancólicas, masoquistas e sádicas, mas sobretudo produzindo perda do investimento egóico e desamparo.

Em contribuição anterior, Campos (2013) caracteriza e discute de forma mais detalhada condição de desamparo e violência no âmbito social contemporâneo, indicando a partir das contribuições de Birman (2006) e Kehl (2000) a necessidade de pensar uma gestão do desamparo a partir da possibilidade de instituição de novos ideais para a regulação e instituição de vínculos sociais. Para tanto, propõe que se considere essa forma revisitada de sublimação em articulação com uma concepção de ação.

A sublimação consiste em um destino que opera uma ação efetiva sobre a realidade e, nesse sentido, pode ser aproximada à uma ideia de práxis, como propõe Birman (2006) ao defini-la como sublime-ação. Trata-se de pensar que as operações de significação e afetação não são apenas do domínio intrapsíquico, mas ações que produzem efeito sobre a realidade compartilhada, deixando suas marcas intencionais no mundo e sendo afetado e transformado por elas, tendo como eixo privilegiado a interação humana e o registro da experiência alteritária. De todo modo, o que se estabelece é uma concepção renovada de subjetividade, que não é estritamente intrapsíquica, mas também intersubjetiva e parte do mundo compartilhado. Nesse sentido é que se pode afirmar que a sublimação é destino privilegiado de ação criativa sobre o mundo e o laço social. Isso se dá em suas duas modalidades, tanto a sublimação que se adapta aos ideais instituídos quanto aquela que institui novos ideais. 
Entretanto, na contemporaneidade, a crise nos valores e falha na consistência dos vínculos acaba por demandar formas instituintes e originais de laço social. Nesse sentido é que ganha relevância a noção de uma instituição de ideais por meio do que Khel (2000) denominou de função fraterna. Retomando o esquema freudiano da dupla vinculação libidinal na constituição dos grupos - a saber, a identificação vertical dos membros com o líder como imago paterna e a identificação horizontal dos membros entre si a partir desse traço identificatório comum - a autora propõe que diante da crise das imagos paternas que sustentam imaginariamente a função simbólica na atualidade, caberia promover e fomentar essa dimensão fraterna. Campos (2013) indica que essa via de ação no vínculo social é justamente o que está em jogo no primeiro tempo da sublimação, de onde decorre sua pertinência para a crítica e ação social hoje em dia. Portanto, cabe resgatar essa dimensão criativa e instituinte dos processos sublimatórios para pensar uma clínica psicanalítica comprometida com a dimensão ético-política do sofrimento. É a sublimação como forma de erogeneização e criação que pode fornecer condições de elaboração psíquica, de ligação em sentido e de ligação em vínculo. É por meio dela que se pode operar cortes em ciclos compulsivos e repetitivos de violência e de submissão; é por meio dela que pode surgir a esperança.

Evidentemente, descrever os processos metapsicológicos de sublimação não é garanti-los ou mesmo condição suficiente para operacionalizá-los. É importante lembrar que ninguém escolhe sublimar e que o próprio encaminhamento desse destino depende de condições complexas de determinação e elaboração, mas circunscrevê-lo e nomeá-lo no âmbito da teoria é fundamental no sentido de ressignificar os próprios ideais norteadores da prática clínica hoje e, portanto, constitui uma importante referência teórica e ética para o campo psicanalítico e para a clínica ampliada, uma vez que esta é comprometida com a dimensão social e política do sofrimento. Nesse sentido é que procuramos indicar a noção de um trabalho de sublimação como um eixo de articulação das diferentes facetas do malestar na contemporaneidade.

\section{CONSIDERAÇÕES FINAIS}

Ao fim desse percurso de reflexões em três níveis tão diferentes de problematização do desamparo no campo social - as psicopatologias atuais, a precarização estrutural do trabalho e a metapsicologia da sublimação procuramos demonstrar como a crise de valores e de ideais na contemporaneidade incide sobre os modos de subjetivação de formas distintas, porém ao mesmo tempo análogas e convergentes com relação às características do individualismo, à perda de referências simbólicas e às formas narcísicas de laço social.

Sendo assim, ao longo deste trabalho, procurou-se estabelecer um eixo de compreensão sobre o desamparo e o mal-estar contemporâneo, suas formas de sofrimento e sua captura em sistemas de codificação e reconhecimento de sintomas que possa ir além das críticas que evidenciam e denunciam limites dentro de uma abordagem ainda setorizada e muitas vezes dicotomizada entre biológico, 
psicológico e sociológico (bio-psico-social). O eixo proposto passou pelo aprofundamento de uma compreensão do trabalho sublimatório sobre as pulsões, abordando seus destinos simultaneamente em sua dimensão individual e coletiva. Reforçamos que a crise da subjetividade moderna se desdobra de diferentes maneiras, porém com destaque para seus efeitos disruptivos no tecido social e nas expressões afetivas que podem ser caracterizadas como experiências de desintegração e desilusão, no que concerne à representatividade institucional e aos processos de subjetivação contemporâneos.

Não só o sintoma é expressão de uma diagnóstica que se constitui em um sistema de codificação e tipificação socialmente instituído e mantido, como a sublimação é um processo que cria vínculos e objetos sociais, aptos à ação humana socialmente partilhada e à possibilidade de expansão das modalidades de reconhecimento do sofrimento psíquico no mundo em que vivemos, para além dos sistemas formais de classificação, produção e ordenação na forma da patologia. Atravessando esses dois parâmetros está o trabalho, que não é mera atividade funcional ou produtiva, mas uma condição de elaboração subjetiva e de realização objetiva. Lembremos a missiva freudiana de que o trabalho é um instrumento que o homem criou para lidar com seu desamparo (Hilflosigkeit) e viver em sociedade.

Por fim, o resgate da dimensão plástica e instituinte dos processos sublimatórios, do trabalho humano e das demandas de sofrimento teve como finalidade última propor parâmetros para pensar o fazer psicanalítico social e eticamente comprometido com a subjetividade humana. Defendemos que esse seja um encaminhamento possível para contribuir no sentido de constituição de vínculos e laços sociais integrativos, que possam também ser potencialmente propositivos de novos ideais para a cultura contemporânea. Também reiteramos a necessidade e urgência de pensar o entendimento e a gestão do desamparo na contemporaneidade por meio de uma clínica psicanalítica que considere o campo social como dimensão estrutural da subjetividade.

\section{REFERÊNCIAS}

Agambem, G. (2017). O uso dos corpos. (S. J. Assmann, Trad.). São Paulo, SP: Boitempo.

Antunes, R. (2018). O privilégio da servidão: O novo proletariado de serviços na era digital. São Paulo, SP: Boitempo.

Barreto, F. P., \& lannini, G. (2017). Introdução à psicopatologia lacaniana. In A. Teixeira, \& H. Caldas (Eds.), Psicopatologia lacaniana 1 - semiologia (pp. 35-54). Belo Horizonte, MG: Autêntica.

Birman, J. (2006). Arquivos do mal-estar e da resistência. Rio de Janeiro, RJ: Civilização Brasileira.

Bocchi, J. (2018). A psicopatologização da vida contemporânea: Quem faz os diagnósticos? DOXA: Revista Brasileira de Psicologia e Educação, 20(1), 97-109. doi:10.30715/rbpe.v20.n1.2018.11309

Butler, J. (2017). A vida psíquica do poder: Teorias da sujeição (Rogério Bettoni, Trad). Belo Horizonte, MG: Autêntica.

Campos, E. B. V. (2013). Sublimação e violência: Destinos da pulsão no social. In C. C. E. Mouammar \& É. B. V. Campos (Eds.) Psicanálise e questões da contemporaneidade - I (pp. 133-148) Curitiba, PR: CRV; São Paulo, SP: Cultura Acadêmica.

Campos, E. B. V., \& Loffredo, A. M. (2019). A metapsicologia freudiana da sublimação. Psicologia em Estudo, 24(1): 1-16. doi:10.4025/psicolestud.v23i0.40557 
Dardot, P., \& Laval, C. (2016). A nova razão do mundo: Ensaio sobre a sociedade neoliberal. São Paulo, SP: Boitempo.

Dunker, C. I. L. (2015). Mal-estar, sofrimento e sintoma: Uma psicopatologia do Brasil entre muros. São Paulo, SP: Boitempo.

Ehrenberg, A. (2009). O sujeito cerebral (Marianna T. de Oliveira \& Monah Winograd, Trad.). Psicologia Clínica, 21(1): 187-213.

Freud, S. (2010) O mal-estar na civilização, novas conferências introdutórias à psicanálise e outros textos (1930-1936) (P. C. Souza, Trad.) In S. Freud, Obras Completas, v. 18 (pp. 10-89). São Paulo, SP: Companhia das Letras. (Trabalho original publicado em 1930)

Freud, S. (2010) Os instintos e seus destinos (P. C. Souza, Trad.) In Introdução ao narcisismo, ensaios de metapsicologia e outros textos (1914-1916) In S. Freud, Obras Completas, v. 12 (pp. 38-60). São Paulo, SP: Companhia das Letras. (Trabalho original publicado em 1915)

Gaulejac, V. (2007) Gestão como doença social: Ideologia, poder gerencialista e fragmentação social. (I. Storniolo, Trad.) São Paulo, SP: Ideias e letras.

Infante, D. P. (2011). Psiquiatria para que e para quem. In A. Jerusalinsky, S. Fendrik (Eds.), O livro negro da psicopatologia contemporânea (pp. 63-71). 2. ed. São Paulo, SP: Via Lettera.

Jones, E. (1989). A vida e a obra de Sigmund Freud (Júlio Castañon Guimarães, Trad.). Rio de Janeiro, RJ: Imago. (Trabalho original publicado em 1953)

Kehl, M. R. (2000). (Ed.) Função fraterna. Rio de Janeiro, RJ: Relume-Dumará.

Loffredo, A. M. (2014). Figuras da sublimação na metapsicologia freudiana. São Paulo, SP: Escuta; Fapesp.

Menezes, L.S. (2008) Desamparo. São Paulo, SP: Casa do Psicólogo (Coleção Clínica Psicanalítica).

Menezes, L. S. (2012). Psicanálise e saúde do trabalhador: nos rastros da precarização do trabalho. São Paulo, SP: Primavera Editorial.

Rosa, M. D. A (2016). A clínica psicanalítica em face da dimensão sociopolítica do sofrimento. São Paulo, SP: Escuta; Fapesp.

Russo, J., \& Venâncio, A. T. A. (2006). Classificando as pessoas e suas perturbações: a "revolução terminológica" do DSM III. Revista Latinoamericana de Psicopatologia Fundamental, IX(3): 460-483.

Safatle, V. (2016). O circuito dos afetos: Corpos políticos, desamparo e o fim do indivíduo. Belo Horizonte, MG: Autêntica.

Seligmann-Silva, E. (2011). Trabalho e desgaste mental: o direito de ser dono de si mesmo. São Paulo, SP: Cortez.

\section{CONFLITOS DE INTERESSES}

Não há conflitos de interesses.

\section{SOBRE OS AUTORES}

Érico Bruno Viana Campos é Professor Assistente Doutor II no Departamento de Psicologia da Faculdade de Ciências de Bauru da Universidade Estadual Paulista "Júlio de Mesquita Filho" (Unesp) e docente efetivo do Programa de Pós-Graduação em Psicologia do Desenvolvimento e da Aprendizagem da FC/Unesp - Bauru. É psicólogo, mestre e doutor em Psicologia pelo Instituto de Psicologia da Universidade de São Paulo (USP). É coordenador do Núcleo de Estudos, Extensão e Pesquisas em Psicanálise (NEEPPSICA) do Departamento de Psicologia da UNESP e líder do Grupo de Pesquisa do CNPq "Psicanálise: Clínica, Teoria e Cultura". É membro do GT "Filosofia da Psicanálise" da ANPOF e do GT "Psicanálise e Clínica Ampliada" da ANPEPP.

E-mail: erico.bv.campos@unesp.br

(iD) http://orcid.org/0000-0002-4716-4163

Lucianne Sant'Anna de Menezes é psicóloga e psicanalista, Professora Associado II no Instituto de Psicologia da Universidade Federal de Uberlândia (IP-UFU) MG, professora permanente do Programa de Pós-Graduação em Saúde Ambiental e Saúde do Trabalhador (PPGAT- IG-UFU), Membro Efetivo 
do Departamento Formação em Psicanálise do Instituto Sedes Sapientiae - SP, Mestre e Doutora em Ciências pelo Instituto de Psicologia da Universidade de São Paulo (IP-USP)-SP, autora dos livros "Pânico: Efeito do desamparo na contemporaneidade. Um estudo psicanalítico" (Casa do Psicólogo/FAPESP, 2006), "Desamparo" (Coleção Clínica Psicanalítica, Casa do Psicólogo, 2008), "Psicanálise e Saúde do trabalhador: nos rastros da precarização do trabalho" (Primavera Editorial 2012), Coordenadora do Laboratório da Intersubjetividade (LABINTER - IP-UFU), Pesquisadora do Grupo de Pesquisas "Psicanálise e Sociedade" (LABINTER-IPUFU), Pesquisadora do Grupo de Estudos e Pesquisa em Migração, Saúde e Trabalho (MIGRAST-UFU).

E-mail: lucianne.menezes@ufu.br

\section{iD http://orcid.org/0000-0002-5989-661X}

Josiane Cristina Bocchi é Professora Assistente Doutora no Departamento de Psicologia, da Faculdade de Ciências de Bauru da Universidade Estadual Paulista "Júlio de Mesquita Filho" (Unesp) e do Programa de Pós-Graduação Mestrado em Educação Sexual (Unesp/Araraquara). Fez aprimoramento profissional em Psicologia Clínica no Departamento de Neurologia, Psiquiatria e Psicologia Médica (HCFMRP-USP, 2000-2002). Doutora em Filosofia (UFSCar, 2010) e Pós-doutoramento pelo Departamento de Psicologia (UFSCar, 2012). É membro do GT "Filosofia e Psicanálise" da ANPOF. As suas principais áreas de conhecimento como pesquisadora e docente são psicopatologia, psicossomática e epistemologia da psicanálise. Atualmente, pesquisa as relações entre corpo, afetos e sofrimento psíquico.

E-mail: josiane.bocchi@unesp.br

(iD) https://orcid.org/0000-0002-2657-9490 